\title{
A multidão contra o social
}

\author{
Não há essa coisa chamada sociedade. \\ - Margareth Thatcher
}

\section{RESUMO}

Este trabalho busca uma compreensão crítica de um fenômeno social associado à idéia de pós-modernidade: a emergência de um modelo de ação pública calcado em questões identitárias, como as de gênero, etnia e sexualidade. Este modelo é generalizado no conceito de "multidão", proposto por Antonio Negri e Michael Hardt, e articula-se mediante uma certa visão comunicacional que privilegia o entendimento e a criação de um "espaço comum" como telos da comunicação para propor a viabilidade de uma radicalização da democracia ocidental.

\section{PALAVRAS-CHAVE}

- comunicação

- multidão

- identidade

\section{ABSTRACT}

This work attempts to create a critical comprehension about a social phenomenon associated to the idea of "postmodernity": the emergence of a public action model based on identity issues as gender, race or sexuality. This model is generalized by the concept of "Multitude", proposed by Antonio Negri and Michael Hardt, and articulated by a certain point of view about communications, which stresses the "understanding" and the creation of a "common space" as the communication's telos in order to propose the viability of a radical democracy.

\section{KEY WORDS}

- communication

- multitude

- identity
U m dos fenômenos que têm chamado a atenção na organização das sociedades contemporâneas desde, pelo menos, meados do século XX é a emergência de novos "atores sociais" com demandas específicas na esfera política relacionadas à questão da "identidade". Se, durante todo o período moderno, a idéia de "classe social" dominou o imaginário das relações e conflitos sociais, outras formas de agrupamento vêm buscando cada vez mais um papel hegemônico (ARONOWITZ, 1992). Chamamos esses agrupamentos "identitários" por girarem em torno de uma certa noção de identidade compartilhada sem se referirem, no entanto, às noções mais universalistas de "povo" ou "classe social". De maneira geral, esses agrupamentos coincidem com a noção já amplamente discutida de "novos movimentos sociais" e atuam, primariamente, em questões de gênero, sexualidade ou etnia. ${ }^{1}$

Essa tendência não faz senão refletir na esfera concreta das relações sociais o âmbito daquilo que Foucault (2005) denomina como "biopolítica", termo do qual Negri e Hardt (2004, p.78) se utilizam para sugerir a indistinção prática entre esferas do agir cotidiano que estariam separadas, ao menos para o pensamento acadêmico típico da modernidade:

The genealogy of resistances and struggles in postmodernity presupposes the political nature of social life and adopts its as an internal key to all movements. This presupposition is basic, in fact, to the concept of biopolitics and the biopolitical production of subjectivity, Here, economic, social, and political questions are inextricably intertwined. Any theoretical effort in this context to pose the autonomy of the political, separate from the social and the economic, no longer makes any sense.

Esse alegado "entrelaçamento" provoca, evidentemente, mudanças qualitativas em cada um dos seus elementos constituintes.

A política, por exemplo, surge (já o denuncia o prefixo pólis) como a forma grega de gerir a cidade. É portanto, um modo de ação público, exercido para além da esfera do òikos (a casa) de onde derivará a idéia de economia. Temos então, pelo menos a princípio, uma polarização entre política e economia ${ }^{2}$ a qual, mais do que uma simples questão semântica, origina uma distinção entre campos do direito. Desde o império romano até as constituições modernas, essa oposição assumirá a forma da "grande dicotomia" entre o direito público e o privado. Como nota Bobbio (2000, p.13), essa dicotomia será a matriz de outras (como as duplas igualdade/desigualdade, lei/ contrato etc) além de receber, de acordo com cada sociedade específica em que se atualiza, uma cono-

\section{Edilson Cazeloto PUCSP}


tação axiológica. É assim que o autor italiano chega à divisão entre Sociedade Civil e Estado, ${ }^{3}$ alicerce fundamental para a compreensão das questões políticas na modernidade. Esta distinção, ainda seguindo o rastreamento histórico proposto por Bobbio, reflete a contraposição fundamental entre pólis e óikos embora, na história das instituições sociais, os dois termos já tenham sido tomados como sinônimos. A dicotomia Sociedade Civil / Estado só ganha a sua feição contemporânea no pensamento de Hegel, com repercussões claras em todo edifício teórico de Marx. De qualquer forma, o que queremos frisar é que as instituições políticas e sociais tendem a trazer em suas raízes históricas essa dicotomia fundamental entre os âmbitos público e o privado, entre pólis e óikos.

Podemos, então, supor que esse entrelaçamento " biopolítico" entre política, economia e cultura, ao romper com o paradigma dominante da constituição social desde o mundo grego, seja um dos elementos da chamada "pós-modernidade" (TRIVINHO, 2001). Esse alinhamento permite que se possa interpretar o surgimento destes novos atores sociais como uma conseqüência daquilo que Lyotard (1986) sugere ser a decadência da legitimidade das "grandes narrativas" modernas e que podemos estender a todo discurso com pretensão universalista. Assim, a polifonia pósmoderna na arena política (movimento negro, feminismo, luta por direitos de sexualidade, povos colonizados, etc) estaria relacionada a uma certa crise da idéia de "público", ${ }^{4}$ entendido como categoria totalizante e universalizante, que cede espaço para a emergência de formas políticas calcadas na idéia de "identidade", como sublinha Bauman (2001, p. 124).

[...] como a idéia de 'bem comum' é vista com suspeição, como ameaçadora, nebulosa ou confusa - a busca da segurança numa identidade comum e não em função de interesses compartilhados emerge como o modo mais sensato, eficaz e lucrativo de proceder. E as preocupações com a identidade e a defesa contra manchas nela se tornam a idéia de interesses comuns (e, mais ainda, interesses comuns negociados) tanto mais incrível e fantasiosa, tornando ao mesmo tempo improvável o surgimento da capacidade e da vontade de sair em busca desses interesses comuns.

A política marcada pela "identidade" 5 deslegitima a presença de um ação coletiva na escala da sociedade. Junto com os metarrelatos (no registro de Lyotard), o pensamento contemporâneo coloca sob suspeição os "grandes sujeitos históricos", tais como o "proletariado", o "povo" ou a "classe social".

E no contexto da biopolítica e da "crise dos metarrelatos", então, que se consolida a chamada "esfera pública não-estatal" e a emergência dos coletivos identitários como uma reação contra as formas "uni- versais" de atuação social, representadas pelo Estado e pelo Partido, mas também pela noção de "Povo" e até de "Humanidade". O universalismo da Nação, do partido ou da classe social é visto apenas como uma estratégia, cujo objetivo é mascarar e legitimar um projeto de dominação. Uma vez que o "universal", de acordo com essa interpretação feita por esses coletivos identitários, só pode existir encarnando-se em um ator particular, não há outro desfecho possível senão a barbárie e a violência para fazer valer a "verdade" de suas posições, contra qualquer interpretação dissonante: o universal só pode existir quando imposto pela violência do dominante.

Buscando uma outra forma de ação política, esses coletivos não visam à tomada do Estado $^{6}$ e não possuem um programa ideológico fixo (não no sentido daqueles que são utilizados por partidos políticos convencionais) mas se abrem a demandas pontuais e provisórias, assim como em grandes diretrizes genéricas (as chamadas "bandeiras", que são mais uma declaração de princípios que um conjunto coerente de objetivos e estratégias).

\section{A multidão}

É nesta chave de pensamento, ligando a emergência de coletivos identitários à crise de legitimidade dos universais típica da pós-modernidade, que nos propomos a ler a idéia de "multidão", de Negri e Hardt (2004), trabalhada também por Virno (2004), entre outros. A multidão é, então, uma tentativa de pensar a possibilidade (e a necessidade) da ação coletiva na escala da sociedade, sem um sujeito público universal (como o partido ou a classe). Esse conceito pode ser compreendido como uma categoria político-social que busca viabilizar uma forma de democracia específica e efetiva, dispensando-se a intermediação e a representação das formas políticas herdadas da modernidade. A multidão é, por esses autores, entendida como um conjunto de "singularidades em rede", que se mantém como singularidades ainda que atuem no espaço coletivo:

The multitude is composed of a set of singularities and by singularity here we mean a social subject whose difference cannot be reduced to sameness, a difference that remains different (Negri; Hardt, 2004, p. 99). Multitude signifies: plurality - literally: being-many - as a lasting form of social and political existence, as opposed to the cohesive unity of the people. Thus, multitude consists of a network of individuals; the many are a singularity (Virno, 2004, p.76).

A idéia de um espaço coletivo povoado por indivíduos singulares coloca em suspensão, de certa forma, a dicotomia entre o público e o privado que caracterizava a maneira historicamente constituída de compreender o social. Nesta nova visão, a esfera pública é condicionada por interesses e projetos "particulares" definidos por uma noção de identidade, ${ }^{8}$ e não por 
uma teleologia. ${ }^{9} \mathrm{Na}$ teoria da multidão, a agenda pública é formulada a partir de questões que, do ponto de vista do pensamento moderno, eram vistas como privadas e essencialmente não-políticas. ${ }^{10}$

Segundo Negri e Hardt (2004, p.86) o agir sociabilidade da multidão é definida pelo desejo de uma democracia radical, que mantenha intacta as singularidades atuantes e recuse as categorias unificadoras.

The party, the people's army, the modern guerrilla force all appear bankrupt from their perspective because of the tendency of these structures to impose unity, to deny their differences and subordinate them to interests of others, If there is no democracy form of political aggregation possible that allows us to retain our autonomy and affirm differences, they announce, then we will remains separate, on our own.

A multidão, portanto, afirma a precedência da subjetividade no social. Essa subjetividade, previnem os autores, não deve ser vista como uma categoria idealista ou auto-poiética. Antes, o surgimento da multidão como força "biopolítica" seria o desdobramento lógico da forma contemporânea do capitalismo global, calcado na exploração do chamado "trabalho imaterial". É essa ancoragem no mundo do trabalho contemporâneo que permite aos autores a construção de toda a teoria da multidão como força de contraposição ao "Império", tal como desenhado em sua obra anterior (Negri; Hardt, 2003). Ao fundar-se sobre o trabalho imaterial, que seria eminentemente comunicativo, o capital estaria dando espaço para o surgimento de "contra-poderes", que podem acabar desestabilizando as "forças imperiais". Isso porque, na idéia de multidão, a comunicação seria sempre inerentemente democrática, uma vez que só poderia existir a partir de um "colocar em comum". A criação, expansão e circulação deste "comum", que, a princípio, não pode ser propriedade de ninguém, é o centro do projeto democrático contido na idéia de multidão. Em sua constituição, cada "singularidade" pode colaborar de forma única, mas o resultado sempre será coletivo, uma vez que será imediatamente "comunicado" ou tornado comum. Assim, a multidão só pode ser pensada como antagônica ao Império com a condição de que a comunicação seja pensada como antagônica à propriedade privada.

É esse "tornar comum", portanto, o elemento necessário à passagem do privado ao público. A capacidade de comunicar-se traduziria os particularismos e os interesses particulares em uma linguagem comum e, com isso, possibilitaria o crescimento da produtividade do trabalho imaterial, ou seja, da própria "vida social", talhada pela biopolítica. A comunicação transformaria, por sua própria virtude, o "individualismo" das demandas identitárias particulares em uma rede de "singularidades" ao estabelecer um solo comum de entendimento e cooperação entre as várias experiências de mundo:
Agricultural labor, industrial labor, and immaterial labor, we argued, along with the productive social activity of the poor, are taking increasingly common characteristics. This becoming common presents the possibility of not only the equality of the various forms of labor but also their free exchange and communication. Producing in common presents the possibility of the production of the common, which is itself a condition of the creation of the multitude (opus cit. p.338). The common does not refer to traditional notions of either the community or the public; its based on the communication among singularities and emerges trough the collaborative social processes of production (opus cit. p.204).

É difícil não perceber nesta argumentação um rastro da idéia habermasiana de "razão comunicativa". Aqui, como em Habermas, o entendimento se põe como telos transcendental da comunicação. Porém, como criticamos em outra ocasião (Cazeloto; Aidar, 2006, p.13), uma das características do capitalismo contemporâneo é justamente a submissão da produção e circulação de bens à lógica da comunicação, ou seja, a imediata (ainda que parcial) adesão dos processos comunicativos (principalmente os mediáticos) à lógica do lucro e, portanto, da razão instrumental.

No capitalismo contemporâneo (dito pós-fordista) a esfera da produção se altera radicalmente. Não se trata, portanto, de um processo de deslocamento da valorização da esfera econômica da produção para a esfera de produção de sentidos (isto é, da comunicação). A própria esfera da produção é reconstruída como esfera da comunicação. A comunicação passa a constituir o processo de construção da identidade de marca, traço fundamental que dá sentido à produção, que se torna, portanto, parte do processo comunicativo sistêmico. (Itálicos do original).

Nada disso escapa à análise de Negri e Hardt (2004, p. 261). No entanto, os autores optam por ignorar essas reflexões para "apostar" na possibilidade de construção de um "agir comunicativo" que não esteja, desde sempre, comprometido com a razão sistêmica. Apostam no poder corrosivo e subversivo do "resto", ou seja, daquele conteúdo irredutível à apropriação porque

Biopolitical production is on the one hand immeasurable, because it cannot be quantified in fixed units of time, and, on the other hand, always excessive with respect to the value that capital can extract from it because capital can never capture all of life (opus cit . p. 146, itálicos do original).

Claro que não se pode também partir da pressuposição de que os fenômenos comunicacionais sejam apenas "razão instrumental" e que, portanto, estariam 
de saída comprometidos com a manutenção do status quo. Tal simplismo tornaria deficiente a compreensão de fenômenos concretos, como as redes de troca de arquivos pela Internet ou a programação colaborativa realizada pelos adeptos do software livre. A questão, do nosso ponto de vista, é que qualquer teoria ou "aposta" que tenha por base os processos comunicativos contemporâneos não pode simplesmente deixar de lado o fato de que eles são o fundamento do processo capitalista contemporâneo de produção e que, portanto, o comprometimento com a produção e acumulação de valor econômico, com a organização social do trabalho e sua conseqüente hierarquização internacional ou com as formas de propriedade privada não é incidental ou marginal.

Certamente cientes das implicações de suas apostas, os autores constroem o conceito de multidão em um ponto estratégico, na metade do caminho entre a constatação de uma forma social concretamente existente e um projeto de reestruturação das instituições democráticas do mundo contemporâneo.

A multidão seria apenas uma tendência, afirmam em vários momentos, mas ancorada firmemente em forças que já estão atuando. ${ }^{11}$ Por se afirmarem que essas forças são um "tendência" ou um "desejo", fica permanentemente aberta a possibilidade de que os mesmos fenômenos sejam lidos de várias maneiras, inclusive contrárias às projeções que delas fazem Negri e Hardt, de forma que nenhuma crítica neste sentido deixaria de estar prevista na própria ambigüidade entre diagnóstico e prognóstico nas idéias expostas.

A saída que resta, então, é buscar uma compreensão das raízes dessa forma de pensar o social como uma "colagem de singularidades", propondo interpretar seus desdobramentos de maneira alternativa. O que pretendemos colocar em relevo não é a pertinência da "aposta" em torno da noção de multidão, mas criticar-lhe os fundamentos a partir de uma visão histórica.

\section{Homo œconomicus}

A ênfase na singularidade típica das manifestações políticas identitárias que reverbera na noção de multidão leva, como dissemos, a uma suspensão da contradição entre política e economia, da maneira como imaginada desde o pensamento grego. Acompanharemos Foucault (2004) para traçar as raízes deste processo.

Foucault inicia seu curso no Collège de France em 1978 pretendendo compreender as transformações naquilo que ele denomina "a arte de governar". Entre outros tópicos, o desenvolvimento de seu raciocínio o leva a atentar mais detidamente à uma forma específica de se exercer a soberania: "arte liberal de governar", que tem como especificidade:

a. A construção do mercado como lugar de legitimação do poder político; b. A limitação do poder estatal com a construção da idéia de "governo útil";

c. A expansão da ação governamental para além do território da nação, com vistas a tirar vantagens do comércio internacional.

A base desta nova forma de governar, na visão do autor, surge no séc. XVIII, com a ascensão de um conjunto de idéias e valores encarnados na figura do Homo œconomicus. Esse termo é utilizado por Foucault para designar uma forma de comportamento, mas também uma visão de mundo específica, calcada na primazia do interesse. O Homo ceconomicus é aquele que quer estar livre para agir publicamente de acordo com seu interesse particular. O homo ceconomicus "constituait une sorte d'atome insubtituable et irréductible d'intérêt" (Foucault, 2004, p. 295).

Essa legitimação do interesse privado como vetor da agenda pública surge, portanto, dentro do contexto do liberalismo econômico. Uma vez que sejam pautados pelo mesmo mecanismo de suspensão da dicotomia público/privado, tanto os coletivos identitários, como a idéia de multidão, podem ter uma origem comum nesta figura desenhada por Foucault. Nossa leitura é que a idéia de homo ceconomicus é capaz de fornecer uma interpretação pertinente para a gênese das formas de ação social baseadas na "identidade", assim como fornecer subsídios para indicar seus possíveis desdobramentos. Para isso, é necessário refletir sobre o modo de ação pública implicado.

Ocorre que, para o Homo cenomomicus, o resultado social de sua ação particular não deve ser considerado um critério válido para qualquer tipo de juízo moral. O social deriva de uma certa lei "mecânica": todos agindo em seu interesse mais egoísta provocariam o bem comum, quase como um efeito acidental benéfico. Essa é a síntese da conhecida metáfora da "mão invisível", de Adam Smith, que representa bem a idéia de Homo œconomicus.

Bauman (2001, p. 84) perceberá a permanência deste modo de pensar o social no momento atual (que o autor denomina "líquido-moderno"). Segundo ele, no mundo contemporâneo, o individualismo, como tal, ascende à condição de categoria coletiva:

O modo como as pessoas individuais definem individualmente seus problemas individuais e os enfrentam com habilidades e recursos individuais é a única 'questão pública' remanescente e o único objeto de 'interesse público'.

Portanto, pode haver mais do que coincidência no fato de que a política calcada em questões identitárias ganhe a cena pública no contexto contemporâneo, quando o capitalismo se encontra sem oponentes e o neoliberalismo se firma como doutrina dominante. A ação pública individual, alicerçada sobre a noção de identidade e interesse, é em todo compatível com a 
manutenção da hegemonia capitalista e com o ideário privatista do liberalismo. É assim que a ex-primeira ministra britânica Margareth Thatcher pôde anunciar, nos anos 80 , que não havia "essa coisa de sociedade". O espaço público é uma multidão de singularidades, cada qual defendendo seu interesse.

Lida a partir deste ângulo que procura reunir historicamente a ênfase no interesse privado e a ação pública individualizada a um certo tipo de visão do mundo calcada no laissez-faire liberal, a idéia de multidão insinua-se como uma forma política da metáfora da "mão invisível". Nela, assim como nas idéias de Smith, o interesse privado é portador de uma "virtude": a de, ao menos potencialmente, produzir o bem comum mesmo que esse não seja o seu objetivo e desde que esses indivíduos não sejam "perturbados". No caso de Smith, as perturbações são forças exteriores ao mercado (como, por exemplo, certo tipo de intervenções estatais) que desequilibram as condições de competição. No caso da multidão, a perturbação vem da "propriedade privada", que inibiria a criação do "comum" e os efeitos positivos da ação individual expressos na concepção de "comunicação":

Perhaps some day in the future we will look back and see how stupid we were in this period to let private property monopolize so many forms of wealth, posing obstacles to innovation and corrupting life, before we discovered how to entrust social life entirely to the common (Negri;Hardt, 2004, p.188)

Assim, podemos trabalhar com a hipótese de que o projeto de "multidão", tal como desenhado por Negri e Hardt, tem, em sua origem, elementos em comum com as teorias econômicas liberais, notadamente no que diz respeito à predominância de uma idéia de "virtude do individual", mas também ao apontar para uma mesma dinâmica de auto-regulação do social a partir do conflito de interesses, sem a interferência de nenhum tipo de "sujeito soberano":

In contrast to the transcendental model that poses a unitary sovereign subject standing above society, biopolitical social organization begins to appear absolutely immanent, where all the elements interact on the same plane. (opus cit, p.337).

A ênfase na "virtude imanente do individual" e na comunicação como forma de regulação social emancipadora, para além de qualquer forma de soberania, é compartilhada por teorias mais facilmente identificáveis com o ideário liberal, como a idéia de "ciberdemocracia" de Lévy (2002, p.115), na qual a comunicação eletrônica possuiria, por sua própria natureza, a capacidade de transformar o governo em uma "máquina útil", ao invés de uma "autoridade transcendente". Da mesma forma que nos modelos liberais, a idéia de multidão sustenta a força emancipatória da redução do poder soberano proporci- onada por uma comunicação que, graças às suas virtudes intrínsecas, colocaria todos os interesses individuais "num mesmo plano", fazendo emergir, assim, uma nova forma de democracia. Resta questionar as possibilidades concretas dessa redução da soberania e do papel da comunicação como força emancipatória.

\section{A vida nua}

Preliminarmente, queremos frisar, acompanhando Giorgio Agamben, que a lógica do Homo œconomicus, embora pareça estar presente em boa parte do universo político contemporâneo, não foi capaz de eliminar definitivamente a chamada "razão de estado" e o estilo de soberania dela derivado. ${ }^{12}$ Ao teorizar, de maneira muito convincente, sobre a "vida nua", Agamben (2002) demonstra que o poder soberano, ainda que disperso e fragmentado, mantém-se sobre o indivíduo, tanto mais no mundo contemporâneo em que o "estado de exceção" se torna paradigma de governo ${ }^{13}$ (Agamben, 2004). A redução dos direitos civis vivida em várias partes do mundo a partir dos atentados de 11 de setembro de 2001, são apenas o exemplo mais visível desta tendência. Mas há ainda que se pensar nos presos sem status jurídico definido nas celas de Guantánamo ou na pena de morte surda imposta por agentes do Estado às populações pobres (preferencialmente os negros) na periferia das grandes cidades brasileiras.

O que Agamben procura demonstrar é que, por mais que se possa falar em "microfísica do poder", "paradigma de rede" ou "sociedade de controle", a violência concreta e sangrenta não teria recuado um único milímetro na chamada "pós-modernidade" e continuaria talhando as hierarquias no mundo globalizado. De maneiras mais espetaculares, como nas guerras que assolam o planeta, ou mais sutis como a difusão global de estilos de consumo, ainda haveria formas de "poder soberano" e, portanto, de desequilíbrios estruturais. A "mão invisível" não estaria (nunca esteve) livre para regular o mundo de acordo com o simples embate de projetos equivalentes e contraditórios, mas obedeceria a uma hierarquia que reflete desigualdades nas práticas do poder. Por exemplo, ela não seria capaz de regular de maneira equilibrada a relação entre o Estado e as crianças que moram na rua, os trabalhadores rurais sem terra, os analfabetos e subnutridos. Nesses e em inúmeros outros casos, alegar a igualdade de direitos na busca de interesses particulares é escamotear a profunda diferença nas condições objetivas de intervir na cena pública.

Da mesma forma, a comunicação não pode ser vista como uma prática neutra, livre da incidência de poderes e desequilíbrios. Mesmo com a proliferação dos meios digitais que, de alguma forma, poderiam apontar para uma "liberação do pólo da emissão" (Lemos, 2006), o fluxo de informações e a capacidade de intervenção no debate público per- 
manecem atados a estruturas hierárquicas e estas estruturas, em última análise, reforçam a permanência de formas de "poder soberano".

Resulta da continuidade destas hierarquias que as forças políticas derivadas do ideal liberal de "autoregulação" e da "virtude do individual" seriam praticamente impotentes para o enfrentamento de questões que, por sua natureza e pertinência, demandam uma organização coletiva na escala da sociedade ou emanem de grupos extremamente marginalizados e desarticulados, ou seja, excluídos do fluxo hierarquizado da comunicação. Para esses casos, os desequilíbrios da comunicação (que estão relacionados aos desequilíbrios da própria sociedade), tendem a reforçar a situação de submissão. Ainda que os "aportes imateriais" destes grupos possam criar efetivamente valores econômicos traduzíveis em termos financeiros (Negri; Hardt, 2004, p. 134) não é possível permitem supor que eles participem de alguma forma da riqueza produzida. Os pobres participam criativamente da multidão, mas, do ponto de vista do acesso aos bens produzidos (materiais ou não), continuam no estado de privação que os caracteriza como pobres. Qualquer teoria que pretenda compreender criticamente as formas desiguais de distribuição de recursos no capitalismo contemporâneo não pode deixar de lado esta face do chamado "trabalho imaterial": é necessário reconhecer que produzir riquezas não é o mesmo que garantir o acesso à riqueza produzida. A extração de mais-valia ganhou novos contornos, mas não foi simplesmente "abolida" no capitalismo contemporâneo. O abandono da idéia de "interesse público" e a pulverização do social em questões identitárias, se conduzem à alguma liberdade individual, o fazem às custas de expor à "vida nua" imensas parcelas da população mundial ao reforçarem a idéia de que cada um pode contar apenas com os seus recursos na solução dos problemas que o afetam. A "privatização" dos efeitos nocivos e indesejados provocados pela globalização do capitalismo que subjaz a esse raciocínio pode estar colaborando para criar as condições políticas necessárias à reprodução das desigualdades, injustiças e violências das sociedades contemporâneas, exatamente da mesma forma que as teorias pós-modernas acusam o Estado e os "discursos universalizantes". Não se trata evidentemente, de prognosticar uma retomada aos grandes projetos coletivos da modernidade, mas é importante admitir que o receio do autoritarismo implícito na noção de "público" e a aposta na "rede de singularidades" pode trazer às sociedades contemporâneas as mesmas formas de opressão que tenta combater. Assim, uma teoria que tenha como fundamento a vocação libertadora da comunicação, sem levar em conta aspectos políticos, econômicos e sociais que permeiam suas formas concretas, corre o risco de apenas fomentar o que pretende criticar. afamecos

\section{NOTAS}

1. Aronowitz, na obra citada, ainda considera o nacionalismo e o fundamentalismo religioso como formas de política calcadas na identidade, assim como inclui entre os "novos movimentos sociais" os grupos que lutam por causas pontuais como a posse da terra ou por moradias urbanas, por exemplo.

2. Para uma história da oposição entre Polis e Óikos, veja-se a entrevista que Giorgio Agamben concedeu a Gianlucca Sacco (2005).

3. Bobbio (200) busca demonstrar como essa distinção, hoje tornada senso comum, origina-se no pensamento de Hegel e ganha força com Marx. $\mathrm{Na}$ história das instituições sociais, os dois termos, Sociedade Civil e Estado já foram aproximadamente sinônimos, mas, na compreensão contemporânea, vale essa divisão na qual as atividades econômicas e culturais permanecem na esfera da Sociedade Civil, enquanto o Estado é o espaço da política e do governo.

4. O declínio da esfera pública é um tema suficientemente bem abordado pelo pensamento sociológico e filosófico, de Habermas a Hanna Arendt. Não problematizaremos nem nos preocuparemos em repetir argumentos aos quais não teríamos nada a acrescentar neste momento, mas nos concentraremos aqui na forma como os coletivos identitários pretendem lidar com essa questão.

5. É bom lembrar que a "Identidade" em Bauman nunca pode ser compreendida de maneira ontológica. Ela é um processo permanentemente aberto e instável, sujeito a negociações e agenciamentos. É nesse sentido que também a compreendemos neste texto. Veja-se Bauman (2005)

6. É neste sentido que Bey (s/d) propõe o levante como estratégia subversiva apropriada que a revolução. Enquanto o primeiro mantém sua força inovadora por ser sempre provisório e temporário, a segunda tenderia sempre a se cristalizar em formas institucionais que terminariam por trair os ideais que a provocaram.

7. "Particular" aqui é utilizado como "negação do universal". Desta forma, a atuação dos coletivos ainda é particular, mesmo que se refira a mais de um indivíduo, uma vez que não se pretende válida a toda e qualquer contexto, mas apenas no interior das demandas que a produziram.

8. Não desconsideramos aqui o fato de que a construção de identidades pode ser, em si, uma questão política. 
9. Mais problemática se torna a questão se considerarmos, como vários autores, que a própria noção de identidade se torna relativamente instável no mundo contemporâneo. Além do já citado Bauman (2005), lembramos que a lista de autores que defendem esse argumento é bastante extensa.

10. As demandas sociais baseadas na sexualidade, como o movimento gay, são, sem dúvida, o exemplo mais claro desta transformação.

11.Em nossa opinião, Negri e Hardt estimulam essa ambigüidade. Ora o que existe é um "desejo de multidão", ora ela é uma construção histórica, imanente às relações capitalistas. É difícil separar o que os autores estão efetivamente vendo no mundo das relações concretas e o que eles gostariam de ver.

12. Foucault (2004), pensa uma passagem da soberania calcada em uma "razão de Estado" para a atual, que se baseia na "razão econômica". Sustentamos, porém, que ambas as esferas coexistem e se determinam reciprocamente. A "razão de Estado" não desaparece e nem se subordina totalmente à razão econômica, mas emerge esporadicamente como modo de ação soberano.

13. É interessante notar que Negri e Hardt retomam esse mesmo trabalho de Agamben quando procuram descrever o paradigma sócio-político contemporâneo. Os autores, no entanto, preferem sublinhar o "desejo de democracia" que parece fadado a transformar o atual "estado de exceção" em uma relíquia histórica.

\section{REFERÊNCIAS}

AGAMBEN, GIORGIO. Estado de exceção. Trad. Iraci D. Poleti. São Paulo: Boitempo, 2004.

- Homo sacer. O poder soberano e a vida nua I. Trad.: Henrique Búrigo BH: UFMG, 2002

ARONOWITZ, Stanley. The politics of identity. New York; London: Routledge, 1992.

BAUMAN, Zigmunt. Identidade. Entrevista a Benedetto Vecchi. Trad. Carlos Alberto Medeiros. Rio de Janeiro: Jorge Zahar, 2005.

—. Modernidade líquida. Trad. Plinio Dentzien. Rio de Janeiro: Zahar, 2001.

BEY, Hakin. T.A.Z. Zona Autônoma Temporária (parte 1). Rizoma.net. Disponível em: http:// www.rizoma.net/ interna.php?id=193\&secao=intervencao. Acesso em: 20/nov./ 2006.
BOBBIO, Norberto. Estado, Governo, Sociedade. Para uma teoria geral da política. São Paulo: Paz e Terra, 2000.

CAZELOTO, Edilson; PRADO, José Luiz Aidar. "Valor e comunicação no capitalismo globalizado". Ecompós - Revista da Associação Nacional dos Programas de Pós-graduação em comunicação. Ed. 6. Ago 2006. Disponível em: http://www.compos.org.br/e-compos/ adm/documentos/ ecompos06_agosto2006_prado_cazeloto.pdf Acesso em: 21/dez/2006.

FOUCAULT, Michel. Naissance de la biopolitique : cours au Collège de France 1978-1979. Paris: Seuil-Gallimard, 2004.

GIDDENS, Anthony. Modernidade e Identidade. Rio de Janeiro: Zahar, 2002.

LEMOS, André. "Ciber-cultura-remix" in ARAÚJO, Denize Correa. Imagem (ir)realidade : comunicação e cibermídia. Porto Alegre: Sulina, 2006.

LÉVY, Pierre. Ciberdémocratie : essai de philosophie politique. Paris: Éditions Odile Jacob, 2002

LYOTARD, Jean-François. O pós-moderno. Trad. Ricardo Corrêa Barbosa. Rio de Janeiro: José Olympio, 1986.

NEGRI, Antonio; HARDT, Michael. Multitude. War and democracy in the age of empire. London: Penguin books, 2004.

— Império. Trad. Berilo Vargas. Rio de Janeiro: Record, 2003.

SACCO, Gianlucca. "Da teologia política à teologia econômica - Entrevista com Giorgio Agamben". Interthesis. Vol. 2, n. 2. Trad. Selvino José Assmann. Florianópolis: Universidade Federal de Santa Catarina, 2005. Disponível em: http:// www.interthesis.cfh.ufsc.br/interthesis4/ trad1_22.pdf. Acesso em: 20/nov./2006.

TRIVINHO, Eugênio. O mal-estar da teoria: a condição da crítica na sociedade tecnológica atual. Rio de Janeiro: Quartet, 2001.

VIRNO, Paolo. A grammar of the multitude. For an analysis of contemporary forms of life. Los Angeles; New York: Semiotext(e), 2004. 